\title{
Analysis of response to 20 generations of selection for body composition in mice: fit to infinitesimal model assumptions
}

\author{
Victor Martinez*, Lutz Bünger, William G. HiLL \\ Institute of Cell, Animal and Population Biology, University of Edinburgh, \\ West Mains Road, Edinburgh, EH9 3JT, UK
}

(Received 26 April 1999; accepted 2 December 1999)

\begin{abstract}
Data were analysed from a divergent selection experiment for an indicator of body composition in the mouse, the ratio of gonadal fat pad to body weight (GFPR). Lines were selected for 20 generations for fat (F), lean (L) or were unselected (C), with three replicates of each. Selection was within full-sib families, 16 families per replicate for the first seven generations, eight subsequently. At generation 20, GFPR in the F lines was twice and in the L lines half that of C. A log transformation removed both asymmetry of response and heterogeneity of variance among lines, and so was used throughout. Estimates of genetic variance and heritability (approximately $50 \%$ ) obtained using REML with an animal model were very similar, whether estimated from the first few generations of selection, or from all 20 generations, or from late generations having fitted pedigree. The estimates were also similar when estimated from selected or control lines. Estimates from REML also agreed with estimates of realised heritability. The results all accord with expectations under the infinitesimal model, despite the four-fold changes in mean. Relaxed selection lines, derived from generation 20, showed little regression in fatness after 40 generations without selection.
\end{abstract}

selection / infinitesimal model / genetic variance / body composition / mouse

Résumé - Analyse de la réponse à la sélection de 20 générations pour la composition corporelle des souris : ajustée aux hypothèses du modèle infinitésimal. Les données provenant d'un programme de sélection divergente ont été analysées pour un indicateur de la composition corporelle des souris : la proportion de tissus adipeux gonadal par rapport au poids corporel (GFPR). Trois répliques de chacune des lignées ont été sélectionnées pendant 20 générations pour l'engraissement (F), la minceur (L), ou non sélectionnées. La sélection fut réalisée dans des familles de pleinfrères, 16 familles par réplique durant les sept premières générations et huit pour les suivantes. A la vingtième génération, le GFPR des lignées $(\mathrm{F})$ et $(\mathrm{L})$ étaient respectivement le double et la moitié de celui de (C). Une transformation logarithmique

* Correspondence and reprints

E-mail: Victor.Martinez@ed.ac.uk 
permet de supprimer l'asymétrie de la réponse et l'hétérogénéité des variances entre ces deux lignées. Les estimateurs de la variance génétique et de l'héritabilité (approximativement de $50 \%$ ) obtenus par le REML avec un modèle animal sont semblables à ceux obtenus en utilisant les premières générations de sélection, les 20 générations de sélection ou les dernières en employant l'information sur le pedigree jusqu'à la population de base. De plus, en utilisant les lignées sélectionnées et les lignées de contrôle, les estimateurs sont similaires. Les estimations REML sont conformes à celles de l'héritabilité. Tous les résultats sont conformes à ceux attendus sous un modèle infinitésimal malgré une variation de quatre fois la moyenne. Les lignées soumises à une pression de sélection plus faible à la vingtième génération, montrent peu de diminution en engraissement après 40 générations sans sélection.

sélection / modèle infinitésimal / variance génétique / composition corporelle / souris

\section{INTRODUCTION}

Selection experiments provide the framework for the study of the inheritance of complex traits and allow the evaluation of theoretical predictions by testing observations against expectations. Depending on the time scale, the objectives of selection experiments may differ. Short-term experiments can be used, for example, to estimate genetic variances and covariances, test their consistency from different sources of information, and estimate the magnitude of the initial rates of response to selection. Long-term experiments are useful for measurement of changes in the rates of response or variances caused by the selection itself. As these changes are dependent on the number, effects and frequencies of the genes which influence the quantitative trait, longterm experiments may provide more detailed information about its underlying inheritance $[11,18,19]$.

In the infinitesimal model introduced by Fisher [12], it is assumed that traits are determined by an infinite number of unlinked and additive genetic loci, each with an infinitesimally small effect. Under this model, changes in variance due to changes in gene frequency can be regarded as negligible, but changes in variance do arise due to the correlation between pairs of loci (linkage disequilibrium) induced by selection, the 'Bulmer effect' [2]. With truncation selection the correlation is negative, so the genetic variance is reduced. After a few generations of selection, equilibrium is reached where no further change in variance occurs, at a level dependent on the selection intensity and heritability of the trait $[2,11,22]$. When the population size is finite, there is an additional reduction in the genetic variance because the within family variance decreases as the inbreeding coefficient increases $[8,35,36]$.

Mixed model methodology using an animal model with a complete numerator relationship matrix enables best linear unbiased predictors (BLUP) of breeding values and best linear unbiased estimators (BLUE) of fixed effects to be obtained. If genetic parameters such as heritability are known, BLUP can be used. Otherwise these can be obtained using restricted maximum likelihood (REML) [22]. Estimates are unbiased by selection and inbreeding, providing both that all the data contributing to the selection decisions are included in an analysis using the animal model and that the assumption of infinitesimally small gene effects holds $[5,13,21]$. Simulations of short-term selection experiments suggest that, if only phenotypic data from later generations are included, 
unbiased estimates of the additive genetic variance in the base population can still be obtained [30]. Little is known, however, about the extent to which this holds when the populations span several generations of selection. It is also not clear how unbiased estimates can be obtained when not all the information about the selection process is available or utilised. Nevertheless, unbiased estimation seemed to be dependent on the population structure in the simulations of van der Werf and de Boer [33]. In the small populations simulated, use of the numerator relationship matrix in the mixed model equations to obtain REML estimates of variances seemed to account for most of the bias due to inbreeding and the 'Bulmer effect', even though records used for selection were excluded. Although estimates of additive genetic variance from the large populations simulated seemed to be biased downwards, they had large empirical standard errors.

The infinitesimal model rests on normal (Gaussian) distribution theory, but when the phenotypes are determined by a finite number of loci, normal distribution theory can no longer be invoked. In effect, the regression of offspring on parents is likely to be non-linear, and under continued selection gene frequencies would change and the genetic variability eventually become exhausted without the introduction of new mutations [3, 19]. If the loci are linked, it is likely that there may be an increase in the degree of linkage disequilibrium induced by selection.

The covariance matrix among breeding values when animal models are utilised in BLUP does not take account of changes in genetic variance associated with changes in gene frequency [22]. Nevertheless, simulation results suggest that even when the true genetic model is defined by a small number of loci, the mixed model methods provide adequate estimates of breeding values, at least in the short term $[7,23]$.

The infinitesimal model is obviously not an exact representation of the genome of any species, but is a useful assumption to make in genetic evaluation. Its adequacy for explaining the underlying variation of a trait has been tested empirically using REML on data from selection experiments spanning several generations of selection. Using data from this laboratory, Meyer and Hill [26] and Beniwal et al. [1] found that selection in mice for appetite and for lean mass, respectively, reduced the additive genetic variance more than expected by linkage disequilibrium and inbreeding under the infinitesimal model. In sheep, Crook and James [6] concluded that the estimates of realised heritability derived from a selection experiment for reducing skin fold score decreased over time, perhaps as a result of large changes in gene frequency. Heath et al. [16] detected a constant increase in the additive genetic variance in a population formed by crosses of inbred lines of mice selected for body weight, and therefore lines were probably not in linkage equilibrium when selection began.

A selection programme in mice was started to develop divergent lines with differing selection objectives in order to produce changes in protein mass, food intake and fat proportion (for details see [14, 28]). The present study concentrates on the first 20 generations of the three replicates of those lines selected divergently for high and low proportion of body fat, and in particular on changes in the variances of fat proportion during the course of selection as a check of the infinitesimal model. Hastings and Hill [14] give further information on the consequences of the first 20 generations of selection on body composition, 
and Bünger and Hill [4] on divergent selection continued subsequently from crosses among the replicate lines for over 40 further generations and on inbred lines derived from these selected lines.

Selection was relaxed in the replicate lines at generation 20, and these were retained for a further period of 40 generations without selection. The outcome of this period of relaxation is presented in this paper as it pertains to the selective forces operating and the infinitesimal model assumptions.

\section{MATERIALS AND METHODS}

\subsection{Population structure and selection procedures}

The selection objective of the lines was to change the proportion of body fat, but without greatly changing lean mass $[9,14,28]$. Selection was practised on the ratio of the gonadal fat pad weight to total body weight of males (GFPR). The gonadal fat pads are discrete depots that can be dissected out quickly and accurately and their size is highly correlated with overall proportion of fat in the body [28]. Lines were selected for 20 generations either for a high proportion of fat (F, Fat lines) or a low proportion of fat (L, Lean lines), or randomly selected (C, Control lines). Three replicates were kept of each line, so there were nine in total. The base population was a three-way cross, made by crossing two inbred lines to form an F1, which was then crossed to an outbred line. After one generation of random mating, the three replicates were derived from different sets of full-sib families, while L, F and C lines of each replicate were derived from the same 16 full-sib families [28]. Subsequently, 16 full-sib families were maintained per replicate until generation eight, after which only 8 fullsib families were raised. Matings of least relationship were made as explained by Falconer [10]. This system does not reduce the average rate of inbreeding when there is selection within families, but delays inbreeding for three or so generations in populations of this size and minimises the variation in inbreeding level within the population each generation. Litter size was adjusted from 6 to 12 pups soon after birth by culling and cross fostering. Mice were weaned at 21 days of age.

Selection within families was carried out during the whole selection experiment, where the best male according to the selection criterion, measured at 10 weeks of age, was chosen from four males of each of the full-sib families [28]. As the gonadal fat pad can be measured only post mortem, males were first mated at about 8 weeks of age and at 10 weeks they were killed, weighed and the gonadal fat pad was dissected out and weighed. In generation 0 , four females were mated per male and the offspring of males with the highest ratio and the lowest ratio formed the $\mathrm{F}$ line and the $\mathrm{L}$ line, respectively, while the offspring of the remaining two males formed the $\mathrm{C}$ line. The same procedure was followed subsequently until generation 20, with four males recorded every generation in each family in the selected lines and two in the controls. The numbers of animals and families, both total numbers and those with phenotypic records in the first 20 generations, are listed in Table I. 
Table I. Numbers of records, numbers of animals in the pedigrees and numbers of families over generations $0-20$.

\begin{tabular}{lccccc}
\hline Replicate & Line & Records & Animals & Sires/Dams & Litters with records \\
\hline \multirow{3}{*}{1} & F & 708 & 2337 & 250 & 223 \\
& L & 726 & 2313 & 248 & 225 \\
& C & 418 & 2269 & 236 & 211 \\
2 & F & 735 & 2467 & 250 & 225 \\
& L & 745 & 2400 & 244 & 217 \\
& C & 455 & 2386 & 237 & 222 \\
3 & F & 703 & 2309 & 247 & 219 \\
& L & 712 & 2291 & 245 & 208 \\
\hline
\end{tabular}

\subsection{Statistical analysis}

\subsubsection{Least squares anal sis of responses}

Least squares analysis of gonadal fat pad ratio (GFPR, the selection criterion) was undertaken with data from each replicate and selection objective separately (F, C and L lines), and subsequently with data combined across replicates.

For the analysis of the lines in each of the replicates the model used was

$$
Y_{i j}=G_{i}+\beta\left(N_{i j}-N_{. .}\right)+e_{i j}
$$

where $Y_{i j}$ is the individual observation for the $j$ th member of generation $i ; G_{i}$ is the fixed effect of the $i$ th generation; $\beta$ is the regression coefficient of GFPR on litter size at weaning fitted as a covariate, $N_{i j}$ is the litter size at weaning in which the individual was raised and $N_{\text {.. }}$ is the mean litter size at weaning; and $e_{i j}$ is the random residual. For the analysis of the different selected lines across replicates, the contemporary group (i.e. replicate $\times$ generation) $(G R)_{i j}$ was fitted as a fixed effect in model (1) instead of $G_{i}$.

The direct selection responses in each of the replicates were estimated from the difference between the least squares means for generations of the selected and the control lines, and the overall responses were obtained from their average. Regression coefficients of generation means on generation number were calculated assuming linearity of the selection responses [11]. Realised heritabilities $\left(h^{2} R\right)$ were calculated from the regression of the line divergence on the cumulative selection differentials. Estimates were calculated using data only from generations 0 to 8 , to give the base population realised heritability, and other estimates using data from the complete selection experiment. The realised selection differentials were calculated as the average difference in performance between selected mice and their respective litter mean, halved because only males were selected. 


\subsubsection{Mixed model anal sis}

Variance components were estimated using REML with a univariate animal model accounting for all the relationships between the individuals [17, 27]. The model used was:

$$
\mathbf{Y}=\mathbf{X b}+\mathbf{Z} \mathbf{a}+\mathbf{W} \mathbf{f}+\mathbf{e}
$$

where $\mathbf{Y}$ is the vector of observations, $\mathbf{b}$ is the vector of fixed effects (generations, generations $\times$ replicates and the regression of GFPR on litter size at weaning), $\mathbf{a}$ is the vector of additive genetic effects, $\mathbf{f}$ is the vector of full-sib family effects (i.e., including non additive genetic and common environmental effects), and $\mathbf{e}$ is the vector of random residuals. $\mathbf{X}, \mathbf{Z}$, and $\mathbf{W}$ are the corresponding incidence matrices relating each observation to $\mathbf{b}, \mathbf{a}$, and $\mathbf{f}$, respectively.

The assumed expectations and covariances of random effects were

$$
\begin{gathered}
E\left[\begin{array}{l}
\mathbf{a} \\
\mathbf{f} \\
\mathbf{e}
\end{array}\right]=\left[\begin{array}{l}
\mathbf{0} \\
\mathbf{0} \\
\mathbf{0}
\end{array}\right] \\
\operatorname{Var}\left[\begin{array}{l}
\mathbf{a} \\
\mathbf{f} \\
\mathbf{e}
\end{array}\right]=\left[\begin{array}{ccc}
\mathbf{A} \sigma_{a}^{2} & \mathbf{0} & \mathbf{0} \\
\mathbf{0} & \mathbf{I} \sigma_{f}^{2} & \mathbf{0} \\
\mathbf{0} & \mathbf{0} & \mathbf{I} \sigma_{e}^{2}
\end{array}\right]
\end{gathered}
$$

where $\mathbf{A}$ is the numerator relationship matrix, $\mathbf{I}$ is an identify matrix, $\sigma_{a}^{2}$ is the variance of additive genetic effects, $\sigma_{f}^{2}$ is the variance of full-sib family effects, and $\sigma_{e}^{2}$ is the variance of residual effects.

Estimates of variances in the base population were obtained using phenotypic and pedigree information from the first eight generations. These analyses included litter size as a covariable and generations were considered as fixed effects when replicates were analysed separately. When the analysis was carried out across replicates the contemporary groups (generations $\times$ replicates) were considered as fixed effects, and litter size at weaning was also included as a covariable. The effect of the selection objective (F, L and C) was not fitted in this analysis, because each line of a replicate came from the same set of full-sib families and is genetically linked to others by the relationship matrix.

Changes in variances over the selection experiment caused by departures from the infinitesimal model were investigated using different approaches. Method I comprised records and pedigrees over the complete 20 generations of the selection experiment. Method II included the phenotypic data only from generations 9 to 20 and all the pedigree information back to generation 0 . The same fixed effects outlined previously were included, but an alternative model with directions of selection fitted as genetic groups was also fitted, except when only one direction of selection was included. Method III comprised analysis of blocks, each of three generations of phenotypic information, for example generations 0 to 2,3 to 5 , etc. Two approaches were utilised: either more phenotypic information was included in turn, to give a total of seven analyses; 
or only three generations of phenotypic information, generations 3 to 5,6 to 8 , etc. and all pedigree information back to generation 0 were included.

All analyses were carried out using REML, with the programs of Meyer [25]. Convergence was assumed when the change in the natural log likelihood between iterations was less than $10^{-8}$. Asymptotic standard errors of the estimates of the heritabilities and full-sib family correlations were calculated by a quadratic approximation [25].

\section{RESULTS}

\subsection{Basic statistics}

\subsubsection{Responses}

Mean values of gonadal fat pad ratio (GFPR) for each replicate of each line are given in Figure 1. These changed considerably during the course of the selection experiment, with a greater change in the lines selected for fatness (F) than in those selected for leanness (L). The control (C) lines maintained a mean close to that of the base population $\left(13.2 \mathrm{mg} \cdot \mathrm{g}^{-1}\right)$, whereas at generation 20 the mean of the $\mathrm{L}$ lines $\left(6.7 \mathrm{mg} \cdot \mathrm{g}^{-1}\right)$ was about half and that the $\mathrm{F}$ lines $\left(28 \mathrm{mg} \cdot \mathrm{g}^{-1}\right)$ was almost double that of the base population.

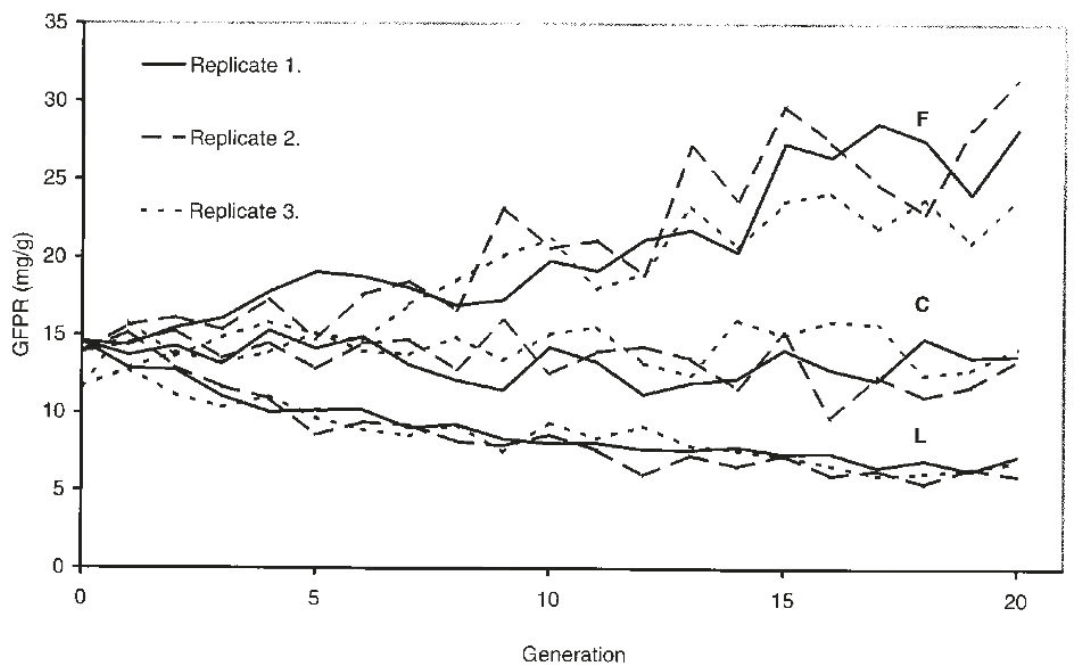

Figure 1. Mean GFPR (original scale, $\mathrm{mg} \cdot \mathrm{g}^{-1}$ ) plotted against generations for all lines and replicates.

\subsubsection{Distributions}

GFPR is a very variable trait, with a coefficient of variation of about $30 \%$ in the control lines. The raw data within lines and generations appeared to depart significantly from a normal distribution (Shapiro-Wilk test, $p<0.05$ ) 
and were positively skewed. The means and variances of the selected lines were strongly correlated, whereas their coefficients of variation appeared to be fairly constant across generations. In order to reduce the heterogeneity of variance and the asymmetry of response in the $\mathrm{F}$ and $\mathrm{L}$ lines, the data were therefore transformed to natural logarithms. The log transformed ratio trait, GFPR, is a linear function of log transformed gonadal fat pad and body weight.

The log transformation gave an approximately normal distribution of the data within lines and generations and removed the association between the generation means and variances in the selected lines. Furthermore, the magnitude of the variances on the log scale did not significantly differ between the selection lines (Bartlett test, $\alpha=0.3$ ). All subsequent analyses of GFPR were therefore undertaken using natural log transformed data.

\subsubsection{Inbreeding}

In the first three generations, the coefficients of inbreeding were essentially zero, after which they appeared to increase linearly and at the same rate in the selected and control lines. The rates of inbreeding were higher after generation 12, as expected because the number of full-sib families was reduced from 16 to 8 pairs per replicate from generation 8 onwards, and there is a lag before this takes effect due to the non-random mating system. The observed rates of inbreeding were approximately $0.80 \%$ /generation from generations 4-11 and 1.65\%/generation from generations 11-20, close to the rates expected for populations with equal family sizes and 16 and 8 mating pairs, respectively. Furthermore, as expected for this mating system, the observed variances of the inbreeding coefficients between families within lines and generations were almost zero.

\subsubsection{Correlated changes in bod weight and litter size}

There appeared to be some divergence in total body weight at 10 weeks between the selected lines (Fig. 2). Analyses undertaken at generation 21 showed that the lines differed little in fat free body weight, but substantially in absolute fat [14].

There was an initial drop in litter size at generation 1, perhaps in part due to reduced heterosis after the previous crossing of founders and in part due to sampling, because fewer litters were recorded in generation 0 . There were no consistent differences in litter size between the lines over the 20 generations (Fig. 3), apart from a slight decline in the L lines. The estimate of linear regression of litter size at birth (assumed to be a trait of the dam) on the individual coefficient inbreeding in the $\mathrm{C}$ line was 0.6 pups per $10 \% \mathrm{~F}$, agreeing closely with values previously reported for mice [10].

\subsection{Least squares analysis}

Changes of GFPR in the $\mathrm{F}$ and $\mathrm{L}$ selected lines were large over the whole selection experiment (Figs. 4 and 5). Responses in GFPR on a log scale were symmetric, the deviations (in natural logs) from the controls at generation $20,+0.74$ for $\mathrm{F}$ and -0.72 for $\mathrm{L}$ being nearly equal. Although 


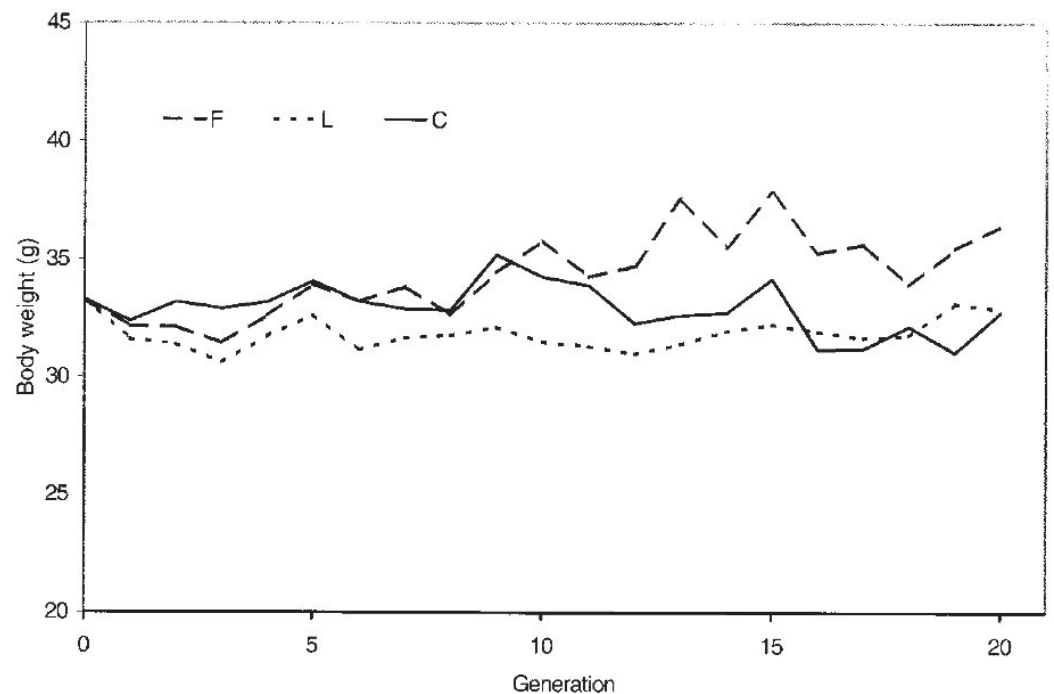

Figure 2. Mean body weight at 10 weeks for males, averaged over replicates, plotted against generations.

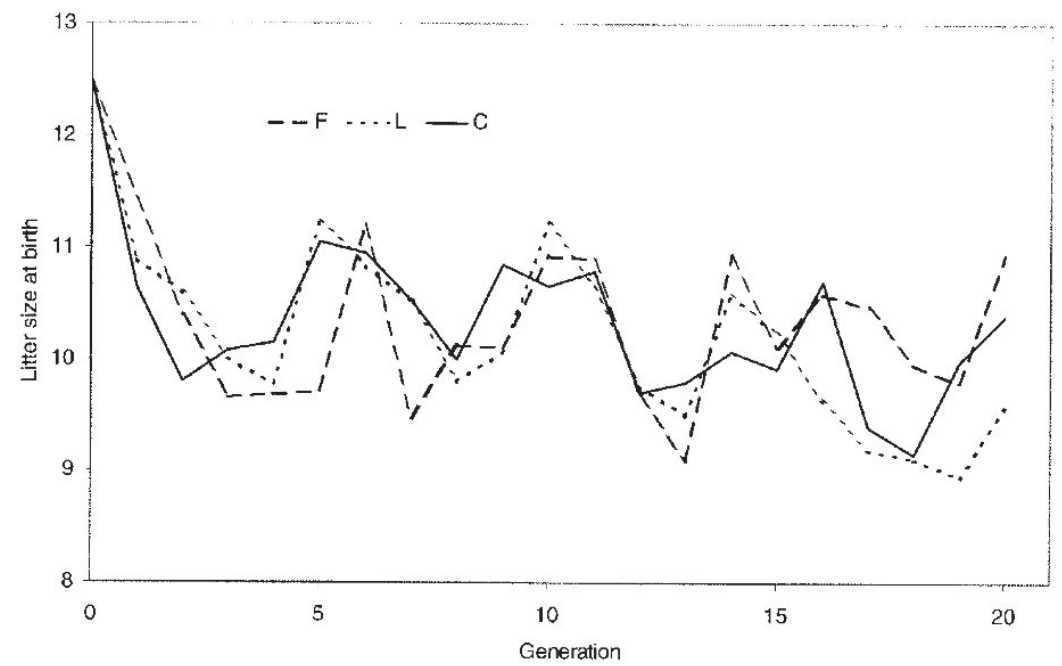

Figure 3. Mean litter size at birth, averaged over replicates, plotted against generations.

substantial responses were obtained in all replicates, there was variation in response among them on the log transformed (not shown) and non-transformed scale (Fig. 1), presumably due to random genetic drift. The divergence was equal to 5.1 phenotypic standard deviations. A decline in the rate of response was observed after generation 16, mainly due to a reduction in the selection differentials from generation 15 onwards to almost half of those previously realised (Fig. 4). The generation means of individual replicates fluctuated more erratically after generation 8 , presumably because fewer animals were recorded. 


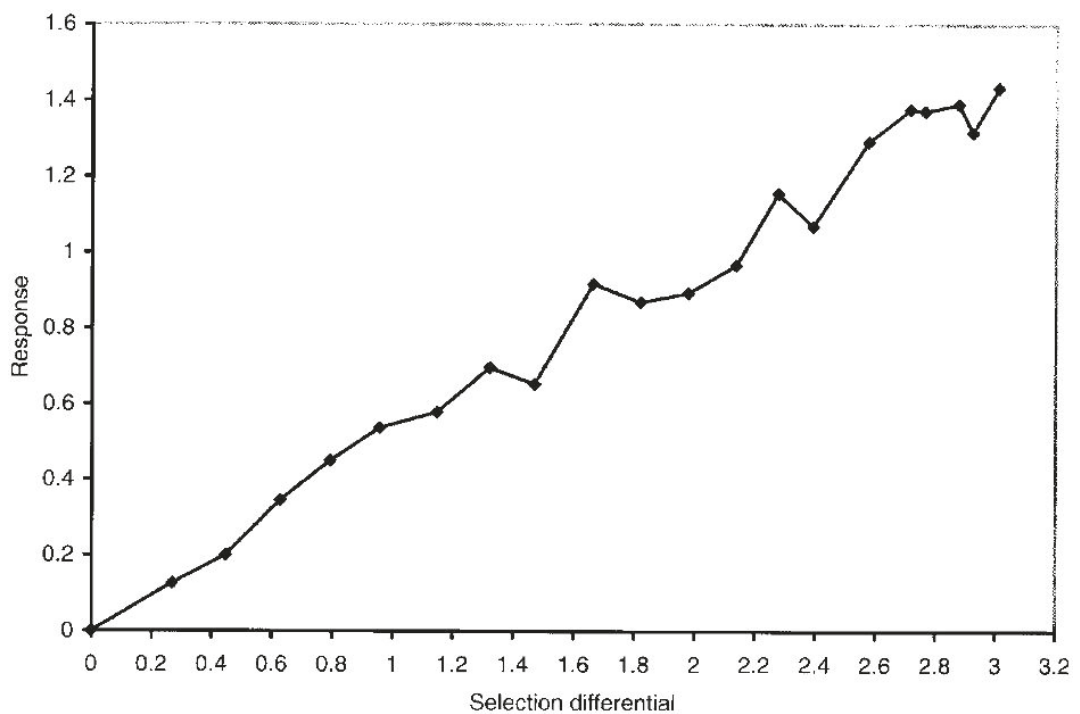

Figure 4. Response to selection in GFPR shown as the divergence between the F and L lines plotted against cumulated selection differential (natural log scale).

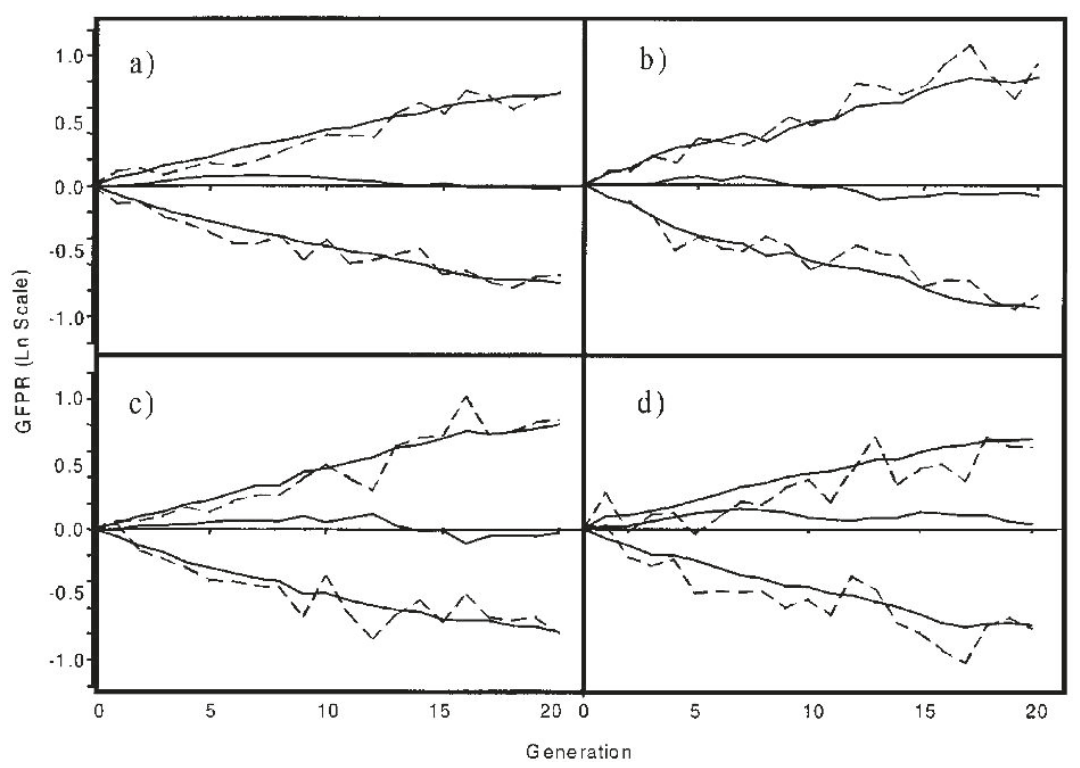

Figure 5. Mean breeding values (PBV) of GFPR (log scale) plotted against generations for males with records, predicted using the animal model (with the values of $h^{2}$ and $f^{2}$ at convergence for each of the analysis). Also least squares means (LBV) for $\mathrm{F}$ and $\mathrm{L}$ lines expressed as deviations from the respective $\mathrm{C}$ lines. (a) Average over replicates, (b) replicate $1,(\mathbf{c})$ replicate $2,(\mathbf{d})$ replicate 3. - - - - F, L (LBV) _ F, L, C (PBV). 
The control line mean was quite steady, although falling slightly after generation 11 (Fig. 1). To determine whether this could be accounted for by inbreeding depression, data from the $\mathrm{C}$ lines were analysed with the inbreeding coefficient of the individuals' fitted as a covariable, in addition to the fixed effects of contemporary groups and litter size at weaning. This analysis suggested there is no inbreeding depression for GFPR, although the estimate is imprecise because inbreeding coefficients varied little within generations.

\subsection{Mixed model analysis}

\subsubsection{Base population parameters (generations 0 to 8)}

The estimate by REML of the individual heritability over all replicates was moderate to high, 0.54 (s.e. 0.03) (Tab. II). The corresponding estimate of within family heritability, $h_{w}^{2}=\left(\sigma_{a}^{2} / 2\right) /\left(\sigma_{a}^{2} / 2+\sigma_{e}^{2}\right)[11]$, is 0.47 . The within family realised heritability $\left(h_{W R}^{2}\right)$, estimated from the regression of the divergence on cumulated selection over all replicates (Fig. 4), was 0.48 (s.e. 0.04 , computed from the empirical s.d. between replicates, although with only 2 d.f.), so the estimates are consistent.

Table II. Estimates using REML of the heritability $\left(h^{2}\right)$, full-sib family correlation $\left(f^{2}=\sigma_{f}^{2} / \sigma_{p}^{2}\right)$, additive genetic variance $\left(\sigma_{a}^{2}\right)$, full-sib family variance $\left(\sigma_{f}^{2}\right)$, residual variance $\left(\sigma_{e}^{2}\right)$ and phenotypic variance $\left(\sigma_{p}^{2}\right)$ for individual replicates and over replicates using data only from generations 0 to 8 (with standard errors of the estimates).

\begin{tabular}{lcccccc}
\hline Line (Replicate) & $h^{2}($ s.e $)$ & $f^{2}(\mathrm{s.e})$ & $\sigma_{a}^{2}$ & $\sigma_{f}^{2}$ & $\sigma_{e}^{2}$ & $\sigma_{p}^{2}$ \\
\hline F + L + C (1) & $0.56(0.06)$ & $0.15(0.03)$ & 0.046 & 0.013 & 0.024 & 0.082 \\
F + L + C (2) & $0.59(0.05)$ & $0.13(0.03)$ & 0.043 & 0.009 & 0.022 & 0.074 \\
F + L + C (3) & $0.50(0.06)$ & $0.18(0.04)$ & 0.042 & 0.015 & 0.028 & 0.086 \\
\hline All (1+2+3) & $0.54(0.03)$ & $0.15(0.02)$ & 0.043 & 0.012 & 0.024 & 0.080 \\
\hline F (1+2+3) & $0.50(0.08)$ & $0.18(0.04)$ & 0.038 & 0.014 & 0.024 & 0.076 \\
L (1+2+3) & $0.50(0.10)$ & $0.17(0.04)$ & 0.037 & 0.013 & 0.025 & 0.075 \\
C (1+2+3) & $0.54(0.09)$ & $0.12(0.05)$ & 0.043 & 0.010 & 0.028 & 0.081 \\
\hline F + C (1+2+3) & $0.49(0.05)$ & $0.18(0.03)$ & 0.039 & 0.015 & 00.26 & 0.079 \\
L + C (1+2+3) & $0.55(0.05)$ & $0.16(0.03)$ & 0.045 & 0.013 & 0.023 & 0.081 \\
\hline
\end{tabular}

There were small, but non-significant, differences among the estimates of heritability using REML from the three replicates. The estimates of the additive genetic variance were, however, more consistent among replicates (Tab. II). When the analyses utilised data from the selected lines separately, the estimates of the additive genetic variance were marginally lower (F 0.038, L 0.037) than obtained overall (0.043) or from the control lines (also 0.043). Because the estimates from single directions of selection do not utilise the selection response, they have standard errors approximately double those obtained from 
the replicates, suggesting that differences may be due to sampling. When data were included from the $\mathrm{F}$ and $\mathrm{C}$ or $\mathrm{L}$ and $\mathrm{C}$ lines, so as to utilise the selection response, rather higher estimates of genetic variance and heritability were found for the $\mathrm{L}$ than $\mathrm{F}$ lines, with standard errors half of those previously noted.

\subsubsection{Method I. Phenot pic and complete pedigree data from generations $0-20$}

When data from all of generations 0 to 20 were included in the REML analysis, estimates of the variance components, heritability (0.55) and within family heritability (0.48) were very close to those estimated for the base population using only generations $0-8$ (Tab. III). There was similar agreement in the analyses of individual replicates and directions of selection (Tab. III). The mean predicted breeding values from BLUP for males with phenotypic records are presented in Figure 5 using estimates of the genetic parameters at convergence from each of the REML analyses over the whole experiment. The BLUP and least squares predictions, the latter expressed as deviations from the corresponding control lines, are compared in Figure 5. In general, there was a very good agreement between these analyses; and the least squares estimates of response, averaged over replicates, overlapped the predicted breeding values (Fig. 5a). Similar consistency was observed in the analyses of the replicates (Figs. 5b to 5d). In the first 8 generations, however, there appeared to be slight differences between the analyses especially for replicate 3 . These may be explained by the slightly positive early trends for GFPR in the C lines, especially during the first 8 generations (see Figs. 1 and 5), and the calculated selection differentials were slightly positive in the $\mathrm{C}$ lines.

Table III. As Table II, but using all data from generations 0-20.

\begin{tabular}{lcccccc}
\hline Line (Replicate) & $h^{2}($ s.e $)$ & $f^{2}($ s.e $)$ & $\sigma_{a}^{2}$ & $\sigma_{f}^{2}$ & $\sigma_{e}^{2}$ & $\sigma_{p}^{2}$ \\
\hline F + L + C (1) & $0.57(0.04)$ & $0.16(0.03)$ & 0.046 & 0.013 & 0.022 & 0.080 \\
F + L + C (2) & $0.58(0.04)$ & $0.14(0.03)$ & 0.042 & 0.010 & 0.020 & 0.072 \\
F + L + C (3) & $0.49(0.04)$ & $0.18(0.03)$ & 0.042 & 0.014 & 00.28 & 0.084 \\
\hline All (1+2+3) & $0.55(0.02)$ & $0.16(0.02)$ & 0.043 & 0.012 & 0.023 & 0.078 \\
\hline F (1+2+3) & $0.51(0.07)$ & $0.19(0.03)$ & 0.038 & 0.014 & 0.023 & 0.075 \\
L (1+2+3) & $0.57(0.07)$ & $0.15(0.03)$ & 0.043 & 0.011 & 0.021 & 0.075 \\
C (1 + 2+3) & $0.56(0.06)$ & $0.13(0.03)$ & 0.046 & 0.011 & 0.026 & 0.083 \\
\hline F + C (1+2+3) & $0.52(0.04)$ & $0.19(0.02)$ & 0.042 & 0.015 & 0.023 & 0.080 \\
L + C (1+2+3) & $0.55(0.04)$ & $0.17(0.02)$ & 0.043 & 0.013 & 0.023 & 0.080 \\
\hline
\end{tabular}

The genetic trend calculated as the regression of the mean of the predicted breeding values on generation number was nearly equal for the $\mathrm{F}$ and $\mathrm{L}$ lines, 0.036 vs. -0.037 (s.e. of each 0.001 ), respectively, as expected from the symmetry in the responses after log transformation (Fig. 5a). 


\subsubsection{Method II. Phenot pic data from generations 9-20 and pedigree information from generation 0}

In order to account for the selection prior to generation 8, genetic groups were fitted in the model as fixed effects [26]. The estimates obtained (Tab. IV) were then very consistent with those for the base population (generations 0-8, Tab. II). The estimates of heritability from the selected lines tended to be slightly higher than for the first period of selection (generations 0-8), but the estimates had high standard errors (Tabs. II and IV). The phenotypic variance is fairly consistent across all analyses.

Table IV. As Table II, but including pedigree data from generations 0-20 and phenotypic data from generations 9-20 only.

\begin{tabular}{lcccccc}
\hline Line (Replicate) & $h^{2}($ s.e $)$ & $f^{2}($ s.e $)$ & $\sigma_{a}^{2}$ & $\sigma_{f}^{2}$ & $\sigma_{e}^{2}$ & $\sigma_{p}^{2}$ \\
\hline F + L + C (1) & $0.59(0.08)$ & $0.18(0.04)$ & 0.047 & 0.014 & 0.018 & 0.080 \\
F + L + C (2) & $0.55(0.08)$ & $0.17(0.04)$ & 0.037 & 00.12 & 0.019 & 0.068 \\
F + L + C (3) & $0.48(0.08)$ & $0.17(0.05)$ & 00.38 & 00.14 & 0.028 & 0.080 \\
\hline All $(1+2+3)$ & $0.54(0.04)$ & $0.18(0.03)$ & 00.40 & 0.013 & 0.022 & 0.075 \\
\hline F (1+2+3) & $0.56(0.12)$ & $0.18(0.05)$ & 0.042 & 0.014 & 0.019 & 0.075 \\
L (1+ 2 + 3) & $0.64(0.09)$ & $0.12(0.04)$ & 0.047 & 0.009 & 0.017 & 00.74 \\
C (1+2+3) & $0.55(0.10)$ & $0.16(0.06)$ & 0.046 & 0.014 & 0.025 & 0.085 \\
\hline F + C (1+2+3) & $0.59(0.05)$ & $0.18(0.03)$ & 0.049 & 0.015 & 0.019 & 0.083 \\
L + C (1+2+3) & $0.64(0.05)$ & $0.15(0.03)$ & 0.054 & 0.012 & 0.017 & 0.084 \\
\hline
\end{tabular}

\subsubsection{Method III. Partition of the phenot pic data into blocks of three generations}

Data from an additional 3 generations were included progressively in a series of analyses. The variance components did not appear to change substantially over the 20 generations of selection (Fig. 6), although estimates of the additive genetic variance from generations $0-3$ were slightly lower than those from later generations. The sampling correlation between the estimates of heritability and the full-sib correlation $\left(\sigma_{f}^{2} / \sigma_{p}^{2}\right)$ is strongly negative, c. -0.7 in the firstthree generations. The data did not have sufficient information to accurately partition the different variance components for, as pointed out by Meyer [24], in populations structured on full-sib families, $\sigma_{a}^{2}$ and $\sigma_{f}^{2}$ have a high negative sampling correlation, especially when data span only a few generations.

When data were restricted to 3 generation blocks, estimates of the heritability tended to increase, from 0.69 at generations $3-5$ to 0.92 at generations 15-17 (Fig. 6), if genetic groups were not fitted. When genetic groups were included in the model the estimates of heritability were near 0.5 during most of the 20 generations of selection, but with a slight increase at generation 15-17 (Fig. 6). The estimates had very large standard errors, but tended to be slightly lower than the overall estimate. 


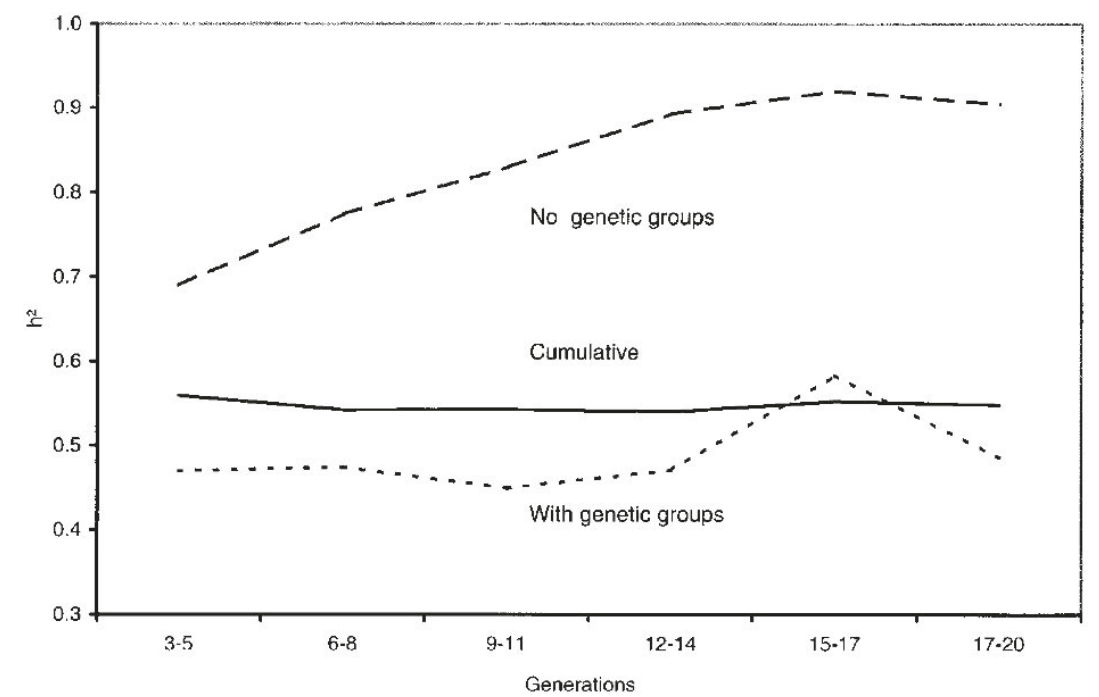

Figure 6. Estimates of the heritabilities $\left(h^{2}\right.$, Method III, replicates pooled) over the course of selection when blocks each of only three generations were included separately in the analysis, either with or without genetic groups fitted. In addition, $h^{2}$ calculated when including information cumulatively.

Although simulation studies of short-term selection suggest that unbiased estimates of the additive genetic variance can be obtained if all the pedigree information but data only from later generations are included [30], the present results show, that it is necessary to account for the changes in line mean caused by the selection practised previously. When genetic groups were not included in the model, but all the pedigree traced back to the base population, the estimates of the additive genetic variance were clearly biased upwards. This seems to be because the animal model can not correctly account for changes in expectations of the random variables, for to do so would require information in the selection not provided in the analysis. Estimates based on the animal model that included genetic groups were, however, very similar to those obtained in the base population.

\section{DISCUSSION}

The aims of this study were: (a) to estimate the selection response in the ratio of gonadal fat pad to body weight, a trait highly correlated with the total percentage of body fat; and (b) to estimate variance components and genetic parameters and changes in them caused by departures from the infinitesimal model.

\section{Selection and genetic parameters of the base population}

Selection had produced significant differences in the proportion of fat, even though within family selection was performed only on males. At generation 20, GFPR at 10 weeks was approximately four times as high in the Fat as in the Lean line, with the response in GFPR being almost symmetric on a log scale, i.e. a doubling in $\mathrm{F}$ and a halving in L. These changes were accompanied 
by substantial changes in total weight of body fat at 14 weeks of age in generation 21 (F $5.7 \mathrm{~g}, \mathrm{~L} 2.8 \mathrm{~g}$, predicted from dry matter content [14]), but not in fat free body weight (F $32.3 \mathrm{~g}$, L $32.5 \mathrm{~g}$ ) (Bünger and Hill, unpublished data). Within family selection, practised in this experiment, has advantages in long-term selection experiments in that the effective population size is at least twice that with random selection [20]. Under the infinitesimal model, selection leads only to a reduction of the variance between but not within families [2], so that the within family realised heritability is reduced only by inbreeding. In this study, the within family realised heritability is very consistent throughout the selection, as is the response to selection, even for data taken only from the last 12 generations when a small reduction would have been expected due to inbreeding. The estimate of within family realised heritability $(0.47)$ agrees closely with the REML estimate of the within family heritability (0.48), which should be free of bias due to selection and inbreeding. These are similar to published values for selection experiments that utilised similar selection criteria [9].

\section{Model assumptions}

Long term selection in experimental populations enables hypothesis about the assumptions of the underlying and unknown mode of inheritance to be tested. Quantitative genetic theory relies mainly in the infinitesimal model, where the underlying mode of inheritance is explained by a large number unlinked genes, each of small effect. In experimental populations over the long term selection significant changes in patterns of response and in the additive variance had been estimated $[1,16]$, indicating departures of the infinitesimal model. Alternative models were considered that could explained such changes [16].

In populations with discrete generations and with control populations available, unbiased estimates of response to selection can be obtained, regardless of the underlying genetic model $[21,29,31]$. This is because the phenotypic means of the selected lines have expectations equal to the genotypic means, regardless of the true genetic model in terms of numbers or effects of loci [32]. In contrast, the mixed model equations rely on the assumption of many unlinked additive genes each with small effects, because changes in variance due to changes in gene frequency are not accounted for in the variance-covariance matrix of random effects in the mixed model equations. Simulations indicate that if the trait is influenced by a small number of genes, mixed model methods give biased estimates of the true genetic means in populations undergoing selection [7]. The agreement between results from the least squares and animal model analyses (Fig. 5) during the 20 generations of selection, suggests that the mixed model methods were adequate to explain the underlying variation of the trait during the part of the experiment when selection response was more or less linear.

The validity of the infinitesimal model can be checked using data from selection experiments by using REML with the animal model to estimate base population parameters from data comprising different numbers of generations [19]. Differences between estimates from different analyses may imply that the infinitesimal model does not hold, because the 'Bulmer effect' and inbreeding are accounted for in the model [29, 30, 31]. For example, Meyer and Hill [26] reported that the decrease in heritabilities was higher than expected from selection and inbreeding in an infinitesimal model and suggested that changes 
in the additive genetic variance were due to changes in gene frequency. The magnitude of their heritability estimates decreased considerably, from 0.24 in the first seven generations to almost 0.07 in the last few generations (up to 23) of selection. In the present study, however, the results fit expectation under the infinitesimal model very well, in the sense that the variance component estimates were consistent over the series of analyses, with no significant decline in the additive genetic variance (Tabs. II-IV and Fig. 6). The heritability estimates agree very closely among all analyses, both when data from the later generations were included in addition to the base population (Tab. III), and when blocks of generations were considered (Tab. IV and Fig. 6), provided the model included genetic groups (Tab. IV).

\section{Relaxed selection}

After generation 20, the replicates from the $\mathrm{F}$ and $\mathrm{L}$ selected lines were maintained with 8 pairs per generation, equal family sizes and no selection. Records of GFPR and other traits were taken in generations 60 to 62 at 10 weeks of age on available lines (only replicates 1 and 2 were retained to generation 60) to check on the effects of relaxation of selection over about 40 generations. Records were also taken on contemporary control lines, founded from the same families in the base population before generation 0 and maintained in the same way as these $\mathrm{C}$ lines, although they were initially used as controls for the lines selected for appetite [28].

Results are given in Table $\mathrm{V}$, which shows the mean of the relaxed lines for each replicate in each of the three generations it was recorded, together with results from generations 19 to 20 (data as Fig. 1) for comparison. Of the large divergence between the selected lines of about 4 to 4.5 fold after 20 generations of continuous selection, about $70 \%$ still remains after 40 generations of relaxed selection (Tab. V). There appears to have been little change in the lean (L) lines, but some regression in the fat $(\mathrm{F})$ lines. As some changes in management took place between generations 20 and 60, the absolute values should not be given too much credence, however.

In generations 21 and 22 there was on average an $8 \%$ or two-fold divergence in total body fat between the selected lines ( $\mathrm{F} 15.5 \%, \mathrm{~L} 7.3 \%)$, predicted from dry matter content at 14 weeks of age (Bünger and Hill, unpublished results). This indicates that selection on one specific fat depot, the gonadal fat pad, has changed the proportion of total body fat to this depot [14], with the Fat (F) lines having a higher proportion. After 40 generations of relaxed selection, the lines differed in total body fat percentage by about $5 \%$, or two-fold, at 10 weeks of age (F 10.8\%, L 5.5\%; predicted from dry matter content, data not shown). Results are not available at later ages on the relaxed lines, but after 10 weeks of age, aggregation of fat is continuous in the $\mathrm{F}$ but negligible in the $\mathrm{L}$ selected lines [15]. Therefore this $5 \%$ divergence is likely to increase in absolute terms with age, suggesting there was little regression in total body fat proportion over the period of relaxed selection.

A comparison of the change in GFPR and total fat percentage over the long period of 40 generations (c. 10 years) of relaxed selection, indicates that natural selection on fatness was weak. Such natural selection as there was appears to be against high rather than low fat content, and affected the selected GFP-depot more than the total body fat. 
Table V. Means $(\bar{X})$, standard deviations (s.d.) for Gonadal fat pad ratio (GFPR), Gonadal fat pad weight (GFPW) and Body weight (BW) at 10 weeks in the selected and control lines for the replicates 1 and 2 (gen. 19-20) and after 40 generations of relaxed selection (gen. 60-62).

\begin{tabular}{|c|c|c|c|c|c|c|c|c|c|c|c|c|}
\hline \multirow{2}{*}{$\begin{array}{l}\text { Generations } \\
\text { Lines/ } \\
\text { Replicate }\end{array}$} & \multicolumn{6}{|c|}{ 19-20 } & \multicolumn{6}{|c|}{ 60-62 } \\
\hline & & $\mathrm{C}$ & & $\mathrm{L}$ & & $\mathrm{F}$ & & $\mathrm{C}^{*}$ & & L & & $\mathrm{F}$ \\
\hline \multirow[t]{3}{*}{1} & & $\mathrm{n}$ & & $\mathrm{n}$ & & $\mathrm{n}$ & & $\mathrm{n}$ & & $\mathrm{n}$ & & $\mathrm{n}$ \\
\hline & & 32 & & 30 & & 31 & & 76 & & 15 & & 38 \\
\hline & $\bar{X}$ & (s.d.) & $\bar{X}$ & (s.d.) & $\bar{X}$ & (s.d.) & $\bar{X}$ & (s.d.) & $\bar{X}$ & (s.d.) & $\bar{X}$ & (s.d.) \\
\hline $\begin{array}{l}\text { GFPR } \\
\left(\mathrm{mg} \cdot \mathrm{g}^{-1}\right)\end{array}$ & 13.7 & $(4.0)$ & 6.8 & (1.6) & 26.1 & $(7.9)$ & 15.2 & $(4.1)^{*}$ & 8.1 & $(2.9)$ & 18.8 & $(5.7)$ \\
\hline $\begin{array}{l}\text { GFPW } \\
(\mathrm{g})\end{array}$ & 0.46 & $(0.16)$ & 0.22 & $(0.07)$ & 0.94 & $(0.34)$ & 0.46 & $(0.13)^{*}$ & 0.18 & $(0.06)$ & 0.57 & $(0.21)$ \\
\hline $\begin{array}{l}\text { BW } \\
(\mathrm{g})\end{array}$ & 33.1 & $(2.8)$ & 32.1 & $(3.8)$ & 35.5 & $(3.6)$ & 30.3 & $(5.2)^{*}$ & 22.8 & $(4.9)$ & 30.1 & $(4.7)$ \\
\hline \multirow[t]{3}{*}{2} & & $\mathrm{n}$ & & $\mathrm{n}$ & & $\mathrm{n}$ & & $\mathrm{n}$ & & $\mathrm{n}$ & & $\mathrm{n}$ \\
\hline & & 32 & & 32 & & 31 & & 76 & & 25 & & 30 \\
\hline & $\bar{X}$ & (s.d.) & $\bar{X}$ & (s.d.) & $\bar{X}$ & (s.d.) & $\bar{X}$ & (s.d.) & $\bar{X}$ & (s.d) & $\bar{X}$ & (s.d.) \\
\hline $\begin{array}{l}\text { GFPR } \\
\left(\mathrm{mg} \cdot \mathrm{g}^{-1}\right)\end{array}$ & 12.6 & $(3.2)$ & 6.2 & $(1.8)$ & 29.8 & $(7.6)$ & 15.2 & $(4.1)^{*}$ & 6.3 & $(3.5)$ & 21.9 & $(3.3)$ \\
\hline $\begin{array}{l}\text { GFPW } \\
(\mathrm{g})\end{array}$ & 0.39 & $(0.11)$ & 0.21 & $(0.06)$ & 1.10 & $(0.34)$ & 0.46 & $(0.13)^{*}$ & 0.21 & $(0.12)$ & 0.74 & $(0.15)$ \\
\hline $\begin{array}{l}\text { BW } \\
\text { (g) }\end{array}$ & 30.7 & $(2.5)$ & 34.0 & $(3.7)$ & 36.4 & $(3.6)$ & 30.3 & $(3.2)^{*}$ & 33.2 & $(3.9)$ & 33.5 & $(3.9)$ \\
\hline
\end{tabular}

* Overall controls of the lines selected for appetite, as explained in the text.

\section{CONCLUSIONS}

Despite producing a four-fold difference by selection between Fat and Lean lines, there was no indication that an infinitesimal model could not describe the data. The additive genetic variance in the base population could be estimated well even after the population had undergone several generations of selection, and there was little evidence of natural selection effects. Therefore standard mixed model procedures that assume multivariate normality and utilise BLUP or REML would be adequate. Furthermore, in a separate experiment, maximum likelihood segregation analysis on crosses of the $\mathrm{F}$ and $\mathrm{L}$ lines after 40 generations of selection was carried out to test for the presence of genes of large effect, but a polygenic additive model was sufficient to describe the data on carcass fat content [34]. The results do not, of course, imply there are infinitely many independent genes all of small effect determining body fatness, but show that, 
in these lines, none had sufficiently large effect to disrupt simple predictions for change in mean and genetic variance from selection.

\section{ACKNOWLEDGEMENTS}

We are grateful to the BBSRC and The British Council for financial support, and to Heli Wahlroos for assistance and helpful comments.

\section{REFERENCES}

[1] Beniwal B.K., Hastings I.M., Thompson R., Hill W.G., Estimation of genetic parameters in selected lines of mice using REML with an animal model 1. Lean mass. Heredity 69 (1992) 352-360.

[2] Bulmer M.G., The effect of selection on genetic variability, American Naturalist 105 (1971) 201-211.

[3] Bulmer M.G., The mathematical theory of quantitative genetics, Clarendon Press Oxford, 1980.

[4] Bünger L., Hill W.G., Inbred lines of mice derived from long-term divergent selection on fat content and body weight, Mammalian Genome 10 (1999) 645-648.

[5] Cantet R.J.C., Birchmeier A.N., The effects of sampling selected data on method R estimates of $h^{2}$, in: Proc. 6th World Congress Genet. Appl. Livest. Prod. University of New England, Armidale, January 1998, Vol. 25, pp. 97-99.

[6] Crook B.J., James J., Assymetry of response to selection for skin fold score in Australian merino sheep, in: Proc. 5th World Congress Genet. Appl. Livest. Prod., University of Guelph, Guelph, August 1994, Vol. 19, pp. 53-56.

[7] de Boer I.J.M., van Arendonk J.A.M., Prediction of additive and dominance effects in selected or unselected populations with inbreeding, Theor. Appl. Genet. 84 (1992) 451-459.

[8] Dempfle L., Statistical aspects of design of animal breeding programs: A comparison among various selection strategies, in: Gianola D., Hammond K. (Eds.), Advances in statistical methods for the genetic Improvement of Livestock, SpringerVerlag, Berlin, 1990, pp. 98-117.

[9] Eisen E., Selection of components for body composition in mice and rats. A review. Livest. Prod. Sci. 23 (1989) 17-32.

[10] Falconer D.S., Replicated selection for body weight in mice, Genet. Res. 22 (1973) 291-321.

[11] Falconer D.S., Mackay T.D., Introduction to quantitative genetics, 4th ed., Addisson Wesley Longman Limited, Essex, England, 1996.

[12] Fisher R., The correlation between relatives on the supposition of mendelian inheritance, Trans. Royal Soc. Edinburgh 52 (1918) 399-433.

[13] Gianola D., Fernando R., Bayesian methods in animal breeding theory, J. Anim. Sci. 63 (1986) 217-244.

[14] Hastings I.M., Hill W.G., A note on the effect of different selection criteria on carcass composition in mice, Anim. Prod. 48 (1989) 229-233.

[15] Hastings I.M., Yang J., Hill W.G., Analysis of lines of mice selected on fat content. 4. Correlated responses in growth and reproduction, Genet. Res. 58 (1991) $253-259$.

[16] Heath S.C., Bulfield G., Thompson R., Keightley P., Rates of change of genetic parameters of body weight in selected mouse lines, Genet. Res. 66 (1995) $19-25$.

[17] Henderson C.R., Applications to linear models in animal breeding, University of Guelph, Guelph, Ontario, 1984. 
[18] Hill W.G., Design of quantitative genetic selection experiments, in: Robertson A. (Ed.), Selection experiments in laboratory and domestic animals, CAB Farnham House, Slough, UK, 1980, pp. 1-13.

[19] Hill W.G., Caballero A., Artificial selection experiments, Annu. Rev. Ecol. Syst. 23 (1992) 287-310.

[20] Hill W.G., Caballero A., Dempfle L., Prediction of response to selection within families, Genet. Sel. Evol. 28 (1996) 379-383.

[21] Kennedy B.W., Use of mixed model methodology in analysis of designed experiments, in: Gianola D., Hammond K. (Eds.), Advances in statistical methods for the genetic Improvement of Livestock, Springer-Verlag, Berlin, 1990, pp. 77-94.

[22] Kennedy B.W., Schaeffer L.R.S., Sorensen D.A., Genetic properties of animal models, J. Anim. Sci. 71 (Suppl. 2) (1988) 17-26.

[23] Mäki-Tanila A., Kennedy B.W., Mixed model methodology under genetic models with small number of additive and non-additive loci, in: Proc. 3rd World Congress Genet. Appl. Livest. Prod., University of Nebraska, July 1986, Vol. 12, pp. $443-447$.

[24] Meyer K., Restricted maximum likelihood to estimate variance components for animal models with several random effects using a derivative free algorithm, Genet. Sel. Evol. 21 (1989) 317-340.

[25] Meyer K., DFREML version 3.0 User notes, University of New England, Armidale, 1998.

[26] Meyer K., Hill W.G., Mixed model analysis of a selection experiment for food intake in mice, Genet. Res. 57 (1991) 71-81.

[27] Patterson H.D., Thompson R., Recovery of inter-block information when block sizes are unequal, Biometrika 58 (1971) 545-554.

[28] Sharp G., Hill W.G., Robertson A., Effects of selection on growth, body composition and food intake in mice, Responses in selected traits, Genet. Res. 43 (1984) 75-92.

[29] Sorensen D., Kennedy B.W., Estimation of response to selection using least squares and mixed model methodology, J. Anim. Sci. 58 (1984) 1097-1103.

[30] Sorensen D., Kennedy B.W., Estimation of genetic variances from selected and unselected populations, J. Anim. Sci. 59 (1984) 1213-1225.

[31] Sorensen D., Kennedy B.W., Analysis of selection experiments using mixed model methodology, J. Anim. Sci. 63 (1986) 245-258.

[32] Su G., Sorensen P., Sorensen D., Inferences about variance components and selection response for body weight in chickens, Genet. Sel. Evol. 29 (1997) 413-425.

[33] van der Werf J.H.J., de Boer I.J.M., Estimation of additive genetic variance when base populations are selected, J. Anim. Sci. 68 (1990) 3124-3132.

[34] Veerkamp R.F., Haley C.S., Knott S., Hastings I.M., The genetic basis of response in mouse lines divergently selected for body weight or fat content. II. The contribution of genes with a large effect, Genet. Res. 62 (1993) 177-182.

[35] Villanueva B., Woolliams J., Gjerde B., Optimum designs for fish breeding programs under mass selection with an application in fish breeding, Animal Sci. 63 (1996) 563-576.

[36] Wei M., Caballero A., Hill W.G., Selection response in finite populations, Genetics 144 (1996) 1961-1974. 